Article

\title{
Projected Changes in Temperature Extremes in China Using PRECIS
}

\author{
Yujing Zhang ${ }^{1}$, Liang $\mathrm{Fu}^{2}$, Jie Pan ${ }^{1}$ and Yinlong $\mathrm{Xu}{ }^{1, *}$ \\ 1 Institute of Environment and Sustainable Development in Agriculture, Chinese Academy of Agricultural \\ Sciences, Beijing 100081, China; angelazyj@126.com (Y.Z.); panjie75@ami.ac.cn (J.P.) \\ 2 Zhejiang Meteorological Observatory, Hangzhou 310017, China; fuliang524@126.com \\ * Correspondence: xuyinlong@caas.cn; Tel.: +86-10-8210-9766
}

Academic Editor: Christina Anagnostopoulou

Received: 28 November 2016; Accepted: 12 January 2017; Published: 17 January 2017

\begin{abstract}
Temperature extremes can cause disastrous impacts on ecological and social economic systems. China is very sensitive to climate change, as its warming rate exceeds that of the global mean level. This paper focused on the spatial and temporal changes of the temperature extremes characterized by the 95th percentile of maximum temperature (TX95), the 5th percentile of the minimum temperature (TN5), high-temperature days (HTD) and low-temperature days (LTD). The daily maximum and minimum temperatures generated by PRECIS under different Representative Concentration Pathways (RCPs) are used in the research. The results show that: (1) Model simulation data can reproduce the spatial distribution features of the maximum temperature (Tmax) and minimum temperature (Tmin) as well as that of the extreme temperature indices; (2) By the end of the 21st century (2070-2099), both the Tmax and Tmin are warmer than the baseline level (1961-1990) in China and the eight sub-regions. However, there are regional differences in the asymmetrical warming features, as the Tmin warms more than the Tmax in the northern part of China and the Tibetan Plateau, while the Tmax warms more than the Tmin in the southern part of China; (3) The frequency of the warm extremes would become more usual, as the HTD characterized by the present-day threshold would increase by $106 \%, 196 \%$ and $346 \%$, under RCP2.6, RCP4.5 and RCP 8.5 , respectively, while the cold extremes characterized by the LTD would become less frequent by the end of the 21 st century, decreasing by $75 \%, 90 \%$ and $98 \%$ under RCP2.6, RCP4.5 and RCP 8.5 , respectively. The southern and eastern parts of the Tibetan Plateau respond sensitively to changes in both the hot and cold extremes, suggesting its higher likelihood to suffer from climate warming; (4) The intensity of the warm (cold) extremes would increase (decrease) significantly, characterized by the changes in the TX95 (TN5) by the end of the 21st century, and the magnitude of the increase in the TN5 is larger than that of the TX95 in the national mean value. The changes in both the TX95 and TN5 are larger under the higher versus weaker emission scenario, indicating that it is essential to reduce the GHG emissions and take adaptation measures in the future.
\end{abstract}

Keywords: extreme temperature; China; RCM; RCP scenarios; global warming; PRECIS

\section{Introduction}

Global warming is already incontrovertible in most parts of the world [1]. Both the daily maximum and minimum temperatures have significantly moved toward the warmer direction in their probability distributions [2,3]. According to observation data, variations in extreme temperature events occurred along with shifts in the temperatures, as there is a positive trend in the extreme warm events and a negative trend in the extreme cold events [1,2]. This trend is supposed to go on through the future, with a larger magnitude in variation [3-5]. Almost all of the regions in the world would experience climate warming, although there are some differences in the forms of the temperature increases, according 
to the multi-model and multi-scenario Coupled Model Inter-comparison Project Phase 5 (CMIP5) simulations [6]. Apart from tropical and some subtropical areas with greater increases in the maximum temperature than the minimum temperature, in most of the land areas in the extratropical regions, there is a steep increase in the minimum temperature and less warming in the maximum temperature [7]. The frequency of the warm days and the length of heat waves would increase and the extreme cold events would decrease significantly, and the changing rate of extreme temperature events related to the minimum temperature would exceed that related to the maximum temperature $[4,8,9]$. Bennett and Walsh noted that the warming rate in the minimum temperature is as much as 2-3 times that of the maximum temperature in Alaska, and this may be attributed to the positive albedo-temperature feedback at high latitude [10]. Min et al. also detected that the anthropogenic GHG emissions have more influence on the extremes related to the minimum temperature [11]. Associated with the asymmetrical warming of the maximum and minimum temperatures, the global mean diurnal temperature range (DTR) decreased in the 20th century [12]. This is a result of natural driving forces, such as radiation, clouds, aerosols, and the features of the underlying surface, as well as anthropogenic activities [13].

The warming rate and magnitude of China is higher than that of the global mean level, according to the Third National Assessment Report on Climate Change [14]. Based on the multi-model ensemble results of CMIP5, the annual mean temperature would increase by $1.7-5.7^{\circ} \mathrm{C}$ by the end of the $21 \mathrm{st}$ century, and the warming trajectories simulated over China are similar to the projected global mean temperature curves for the corresponding Representative Concentration Pathways (RCPs), although there are some differences in the simulated warming rates $[15,16]$. As far as the current situation is considered, the magnitude of warming is larger in the winter and smaller in the summer [17], and it warms more in the inland areas of northwest China than the southeast coastal areas in general [18]. The frequency and intensity of heat wave events have increased generally in the past half-century [19], and the range and frequency of the heat wave duration index would increase in the future. In the eastern part of China, all of the five hottest summers in the observed record appeared since 2000, and the anthropogenic emissions of GHGs can be implicated in the increasing frequency of the extreme hot events [20]. However, the record may be continually refreshed, with 2015 being the warmest year on record for China, according to the China Climate Bulletin issued by the China Meteorological Administration [21]. The cold nights and warm nights, which are based on the daily minimum temperature, have decreased by $3.8 \%$ and increased by $2.8 \%$, respectively, while the cold days and warm days, which are based on the daily maximum temperature, have decreased by $2.1 \%$ and increased by $1.8 \%$, respectively. Additionally, the variation range of the extreme temperature events related to the minimum temperature exceeded that for the maximum temperature. The frequency of extreme cold events clearly decreased in Northeast and North China, whereas the extreme warm events increased more obviously in South, Southwest and Northwest China [22]. The frost days in China decreased as a whole, along with an increasing growing season length [23]. Liu et al. showed that the colder areas in China would be more sensitive in response to climate warming [24], and Ji and Kang noted that the variation in extreme temperatures is more intense in the Tibetan Plateau [23].

Extreme climate events are always linked to low occurrences but can lead to severe impacts on agriculture, the ecosystem, the social economy [19,25], and even human health, as Yang et al. showed that non-accident mortality would increase by $0.47 \%$ with an increase of $1{ }^{\circ} \mathrm{C}$ in the diurnal temperature range [26]. Generally, the more extreme the climate event, the greater the impact on society and the environment it may cause [27]. However, more extreme climate events occur less frequently, and the rarity of occurrence will increase the uncertainty in the analysis. This paper focused on better understanding the possible features in the variation of extreme temperatures under several possible scenarios to provide suggestions to decision makers so that the extreme temperature indices that reflect the "moderate extremes" are chosen, defined by percentile-based thresholds of meteorological variables, typically occurring several times per year, which is a compromise between uncertainty and reliability.

Global climate models are useful tools for simulating mean and extreme climate changes in future climate scenarios $[6,9,28,29]$. The reliability of these projections is increasing, owing to advances in 
modeling and the understanding of the physical processes of the climate system [19,30]. Regional climate models can better resolve the local land-surface properties and the internal regional climate variability through their better resolutions of atmospheric dynamics and processes, which can meet the urgent need for targeted projections of regional climate change. Provide REgional Climates for Impacts Studies (PRECIS) is a dynamic downscaling method developed by the Hadley Centre of the Met Office that can provide developing countries with detailed climate change scenario data. It is widely used in developing countries or regions in analyzing potential changes in the climate extremes [5,31]. Liu et al. applied simulated maximum and minimum temperature data under the SRES A1B scenario produced by PRECIS and predicted that in the future, both of the maximum and minimum temperatures will be higher than the baseline level, with the warming rate of the minimum temperature being as much as 1.1 times the maximum temperature and the DTR decreasing in the northern part of China and increasing in the eastern part of Southwest China [32]. In our paper, simulated data are produced under the up to date emission scenarios recommended by the International Panel on Climate Change (IPCC) Fifth Assessment Report (AR5), namely, RCPs, which have been involved in CMIP5. Our research has some common points with Liu et al. but is more comprehensive and goes more in depth to provide an update and complement to their study.

There is a pressing need for regional projections of the extreme temperature events in China, considering the recent increases in the temperature extremes. The simulation ability of PRECIS and its up-to-date projections based on the RCP scenarios for extreme temperatures over China have not been analyzed before, so this is the first attempt to analyze the changes in extreme temperature events using PRECIS. In addition, previous studies primarily focused on the national trends of temperature extremes in China. However, China has a wide and diverse panel of climate types, which may respond differently to climate warming, so that the regional changes in temperature extremes are given more attention in this paper. The regional climate modeling system (PRECIS), the simulated climate data and the observation data, as well as the extreme temperature indices, are introduced in Section 2; the validation of the simulation capability of PRECIS for the maximum and minimum temperatures as well as the extreme temperature indices and the projection of the variations in extreme temperature events are analyzed in Section 3; and the conclusions and a discussion of the results are provided in Section 4. A map of China and the sub-regions in our description is shown in Figure 1. The division into eight sub-regions is mainly based on administrative regions, which is in accordance with the Third China's National Assessment Report on Climate Change [14]. Additionally, each of the administrative provinces has been given a fixed value in PRECIS, so it is convenient to calculate the regional average value. However, the Inner Mongolia Autonomous Region is divided into three parts, for it spans too wide in longitude, and there is an overlap among the Tibetan Plateau, Southwest China and Northwest China because of the particularity of the geographical position of this region.

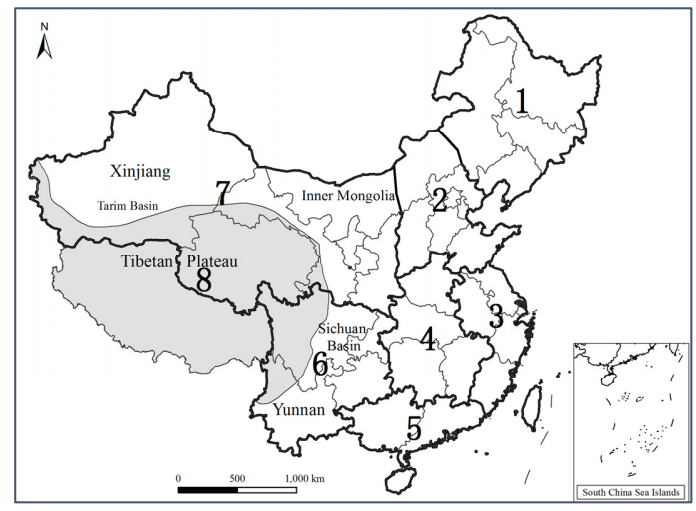

Figure 1. Division of Chinese territory into administrative regions. Zones 1-8 represent Northeast China (NEC), North China (NC), East China (EC), Central China (CC), South China (SC), Southwest China (SWC), Northwest China (NWC), and the Tibetan Plateau (TP), respectively. Zone 8 overlaps with Zones 6 and 7. 


\section{Data and Methods}

\subsection{Model Data}

This research is carried out under future climate change scenarios, including a mitigation scenario with low radiative forcing (RCP2.6), a moderate scenario with stabilized radiative forcing by the end of the 21st century (RCP4.5) and a high concentration scenario with rising forcing (RCP8.5) [30]. The projected daily maximum and minimum temperatures over the period of 1961-2099 are generated using the latest version of PRECIS, version 2.0 [33] In this study, the model resolution is $0.44^{\circ}$ (latitude) by $0.44^{\circ}$ (longitude) $(50 \mathrm{~km})$ with 19 vertical levels. The prognostic variables in the dynamical core include the surface pressure, wind components, water content (vapor plus liquid), cloud ice and potential temperature adjusted to consider latent heat.

For downscaling the GCM under the RCP scenarios, PRECIS 2.0 is driven by the coarse resolution output of HadGEM2-ES, which is a coupled atmosphere-ocean model from the Hadley Centre of the Met Office [34] and one of the models used in CMIP5. The atmospheric component is coupled with the ocean and land surface ecosystem, as prescribed for CMIP5. The resolution of the atmospheric component is $1.875^{\circ}$ (longitude) $\times 1.25^{\circ}$ (latitude) with 38 vertical levels, and the ocean component resolution is $1^{\circ}$ (increasing to $1 / 3^{\circ}$ at the equator) with 40 vertical levels. HadGEM2-ES also contains interactive land and ocean carbon cycles and dynamic vegetation.

\subsection{Observation Data}

The interpolation of the observed meteorological data is also applied to establish the extreme temperature indices to test the applicability of the indices and the validity of the simulated results. The datasets were derived through interpolation by $\mathrm{Xu}$ et al. from the observed daily maximum and minimum temperature data of 751 meteorological stations within mainland China in 1961-2005 with a resolution of $0.5^{\circ}$ (latitude) by $0.5^{\circ}$ (longitude) [35]. The resolution of the interpolated observation data is very close to the PRECIS resolution, so there is not a significant bias for the direct comparison in the statistical analysis.

\subsection{Methods}

Data quality control efforts [36] were made to the model simulated data, including that: (1) Eliminating outliers. Searching for the data that are outside a range of the four standard deviations of the climatologically mean value for the day in each grid, assuring the used data are within the range of the mean $\pm 4 \times$ std. (2) The internal consistency test: Checking for erroneous data, such as when the Tmax is less than Tmin on the same day. The suspected data are treated as missing values. To assess the simulation ability for the surface maximum and minimum temperatures, the downscaled climate simulation data in 1961-1990, which is taken as the baseline period, are compared with the observation data in the spatial distribution. The changes in the extreme temperature indices in 2070-2099 are shown as their differences compared to the baseline level, and the time series of the maximum and minimum temperatures as well as the extreme hot/cold days are displayed as 20-year running average values.

The extreme temperatures will be analyzed from the annual mean maximum temperature (Tmax), annual mean minimum temperature (Tmin), 95th percentile of the maximum temperature (TX95) and 5th percentile of the minimum temperature (TN5), which are the thresholds for the extreme high and low temperature days; they would also allow highlighting the projected changes in the temperature extremes of each grid cell by comparing the average temperature over 2070-2099 to that in 1961-1990. The high-temperature days (HTD) and low-temperature days (LTD) show how usual extreme temperature events based on present-day levels might become in the future. Detailed descriptions of the indices are provided in Table 1. 
Table 1. Definitions of extreme temperature indices used in this study.

\begin{tabular}{cllc}
\hline Code & \multicolumn{1}{c}{ Index } & \multicolumn{1}{c}{ Description } & Unit \\
\hline TX95 & Threshold of extreme hot days & 95th percentile of all of the maximum temperatures & ${ }^{\circ} \mathrm{C}$ \\
\hline TN5 & Threshold of extreme cold days & 5th percentile of all of the minimum temperatures & ${ }^{\circ} \mathrm{C}$ \\
\hline HTD & High-temperature days & $\begin{array}{l}\text { Number of days in a year with the maximum } \\
\text { temperature exceeding TX95 (over 1961-1990) }\end{array}$ & day \\
\hline LTD & Low-temperature days & $\begin{array}{l}\text { Number of days in a year with the minimum } \\
\text { temperature below TN5 (over 1961-1990) }\end{array}$ & day \\
\hline
\end{tabular}

\section{Results}

\subsection{Validation of Extreme Temperature Indices in the Baseline Period}

It is shown in Figure 2 that PRECIS has a considerable simulation capability in the maximum and minimum temperatures of China. It can reproduce the spatial distribution of the annual mean maximum and minimum temperatures that are known to decrease from the southeast to the northwest of China, as well as the high- and low-value centers. For the maximum temperature, the simulation data is slightly higher than the observed data in the southern part of NC and the northern part of EC, as well as the basin area in Xinjiang, while it is lower in TP and the surrounding areas. We can also see from the curves of the probability distribution functions that the simulation data shifted negatively in the lower values below $2{ }^{\circ} \mathrm{C}$, which means an underestimation in the low values and an overestimation of the low-value extent; the simulation extent is less than the observation in the medium-value area in $2-15{ }^{\circ} \mathrm{C}$; and in the higher values above $15{ }^{\circ} \mathrm{C}$, the simulation data shifted in the warmer direction, which means an overestimation in the high-value areas.

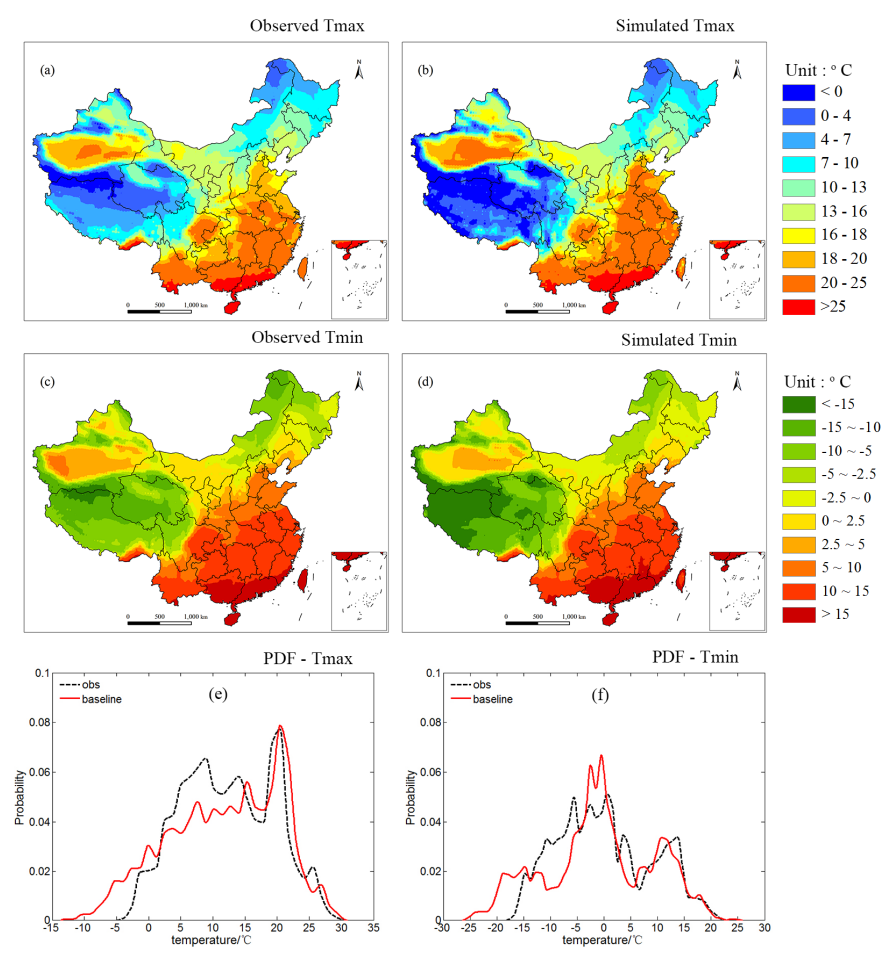

Figure 2. Distributions and probability distribution functions (PDFs) of the maximum and minimum temperatures under observation and simulation in the baseline period: (a) observed maximum temperature; (b) simulated maximum temperature; (c) PDFs of the maximum temperature under observation (black line) and simulation (red line); (d) observed minimum temperature; (e) simulated minimum temperature; and (f) PDFs of the minimum temperature under observation (black line) and simulation (red line). 
For the minimum temperature, the simulated data are higher than the observations in the northern part of SC and the northwestern part of NEC, while it is lower than the observations in the western part of China, including the Tarim basin, the western part of Inner Mongolia and most of the area in TP. From the PDFs of the observation and simulation, we can see that the simulated data are lower than the observed data in the regions below $-15^{\circ} \mathrm{C}$; the simulated extent is clearly less than the observation in the range of $-15--5{ }^{\circ} \mathrm{C}$ and more than the observation in the range of $-5--2{ }^{\circ} \mathrm{C}$; and there are few discrepancies between the simulation and observation in the regions above $2{ }^{\circ} \mathrm{C}$. We can also infer from the PDFs of the maximum and minimum temperatures that PRECIS has a better simulation ability in the higher-value areas.

It is depicted in Figure 3 that PRECIS can generally reproduce the spatial distribution and its changing features along with the latitude and longitude, and it can also reflect the high- and low-value centers of the TX95 over 1961-1990. However, there are still some differences between the simulation and observation, e.g., there is a general overestimation in most parts of China apart from the Tibetan Plateau, with an overestimation of more than $2{ }^{\circ} \mathrm{C}$ in NWC, NEC, the southern part of NC, western part of EC, eastern part of CC, western part of SC and the Sichuan Basin. However, the simulation is lower than the observation in the southern and eastern parts of TP.
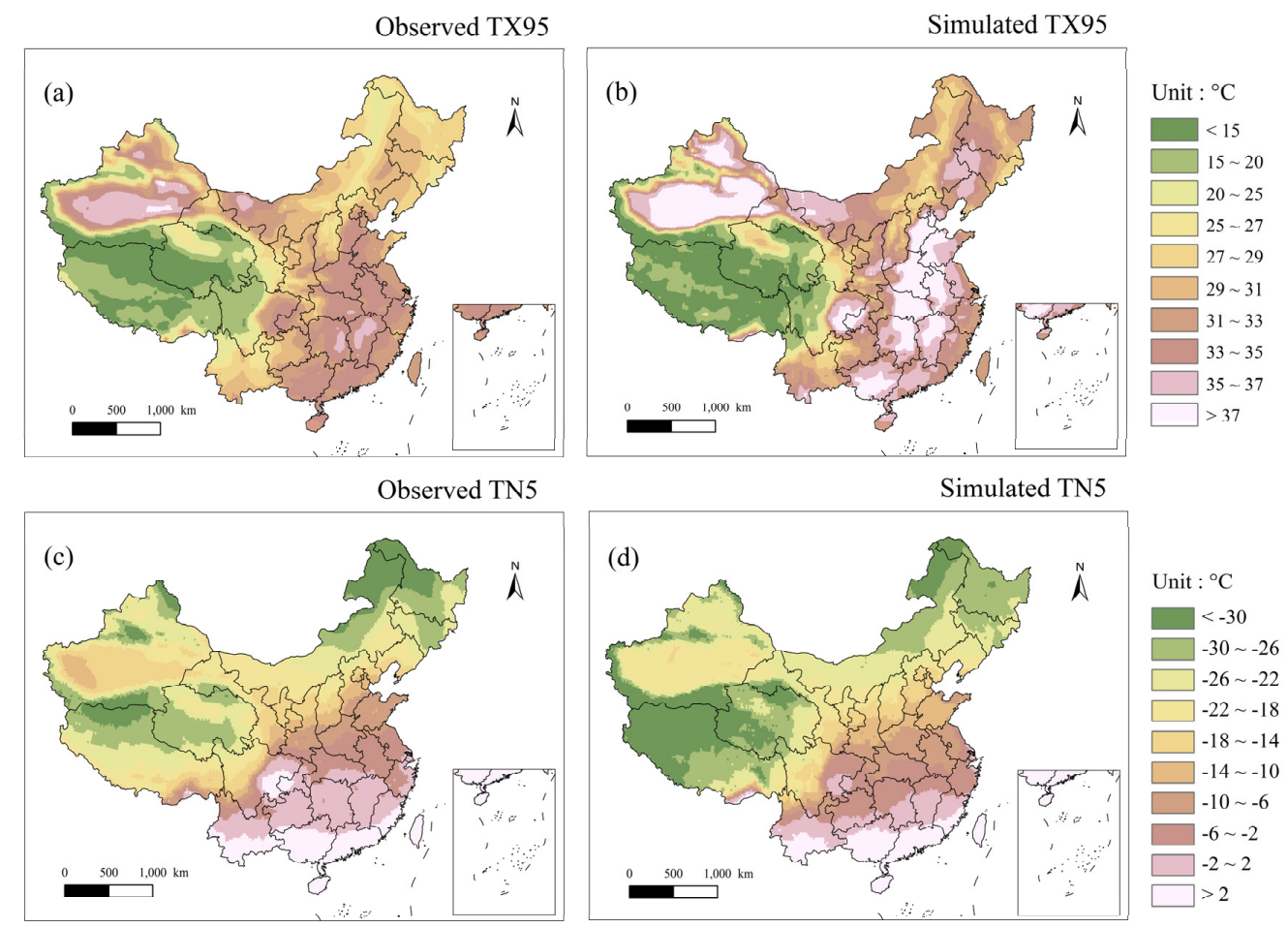

Figure 3. Distribution of the TX95 and TN5 under observation and simulation in baseline period: (a) observed TX95; (b) simulated TX95; (c) observed TN5; and (d) simulated TN5. Unit: ${ }^{\circ} \mathrm{C}$.

The simulation ability for the TN5 is comparable to that for the TX95 in the spatial distribution features, but there is an underestimation of the TN5 in general. For example, there is quite an underestimation of the TN5 in the western part of China, including the basin regions in Xinjiang, most areas on the TP, and the Sichuan Basin, as well as the regions in $-2-2{ }^{\circ} \mathrm{C}$ that are located in the central part of China. There will be a detailed discussion of the bias in Section 4 .

\subsection{Projections of Extreme Temperatures in China under RCP Scenarios}

Figure 4 shows that, by the end of the 21st century, the Tmax and Tmin would significantly increase over the baseline level within China's boundary, but there are some discrepancies in the 
spatial variations between the Tmax and Tmin. The Tmin warms more than the Tmax in NEC and NWC as well as the TP, mainly centered around the cold and high-elevation regions, while the Tmax warms more in the eastern part of SWC and the southern regions of the Yangtze River, which are the relatively warmer areas in China. Under different RCP scenarios, the regions where there are smaller increases in Tmax are mainly located in the Tibetan Plateau, Yunnan Province and the southern part of SC, while there are discrepancies in the regions where there is larger warming in the Tmax under different RCP scenarios. Under the RCP2.6 scenario, larger increases in Tmax appear in CC and the eastern coastal areas, with a magnitude of $2.5-3.5^{\circ} \mathrm{C}$, while it would increase by less than $2{ }^{\circ} \mathrm{C}$ in most areas in NEC, Yunnan Province and the TP. For the RCP4.5 scenario, the Tmax in the northern part of Xinjiang, the eastern part of NWC and the western part of CC would increase by more than $4{ }^{\circ} \mathrm{C}$, while the less warmed areas such as the TP, Yunnan Province and the southeastern coastal areas would increase by approximately $2.5-3.5^{\circ} \mathrm{C}$. The spatial pattern of the increase in Tmax under RCP8.5 is similar to that of the RCP4.5 scenario, but the warming magnitude is larger, and most parts of China may experience an increase of more than $6{ }^{\circ} \mathrm{C}$ over 2071-2099, except for Yunnan Province and the southern part of SC, with increases of $4.5 \sim 5^{\circ} \mathrm{C}$.
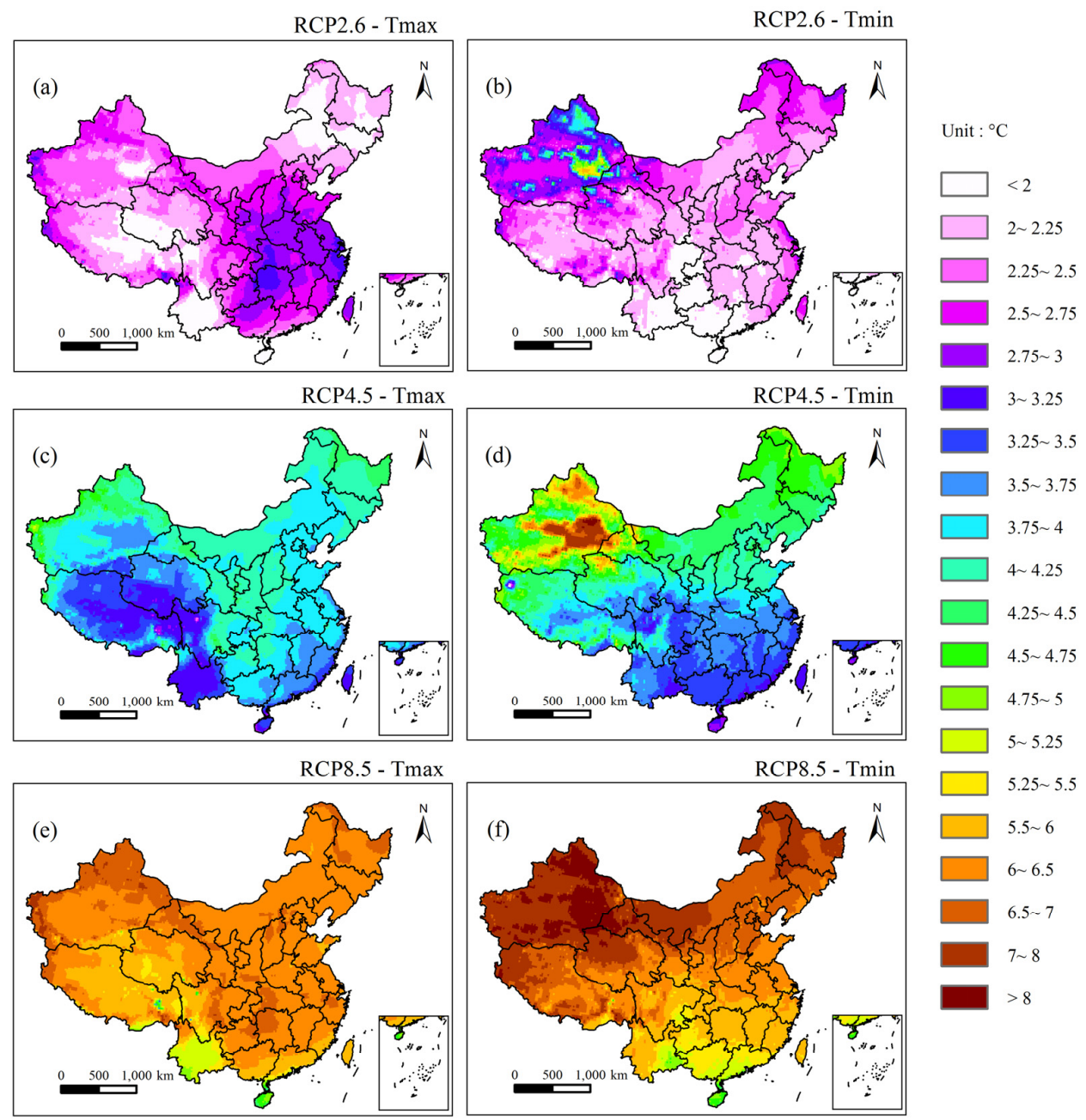

Figure 4. Changes of the maximum (left) and minimum (right) temperatures compared with the baseline period levels under the RCP2.6, RCP4.5 and RCP8.5 scenarios by the end of the 21st century: (a) changes in maximum temperature under the RCP2.6 scenario; (b) changes in minimum temperature under the RCP2.6 scenario; (c) changes in maximum temperature under the RCP4.5 scenario; (d) changes in minimum temperature under the RCP4.5 scenario; (e) changes in maximum temperature under the RCP8.5 scenario; and (f) changes in minimum temperature under the RCP8.5 scenario. 
The warming magnitude in the Tmin increases from south to north in China because of the positive albedo-temperature feedback in the high latitudes. The model tends to simulate larger increases in NWC and NEC as well as the TP, with the largest warming centered on the basin areas in Xinjiang. The smaller increasing areas in Tmin are located in the southern part of China, including the southeastern part of SWC and southern part of SC. When the warming magnitude over 2071-2099 is compared with the baseline level, under the RCP2.6 scenario, the largest increases in Tmin tend to appear in NWC, where there is a $4-5^{\circ} \mathrm{C}$ increase in the warming center that is located in the eastern part of Xinjiang. There is also a larger warming in NEC, the eastern part of EC and the southern part of TP, more than $2.5^{\circ} \mathrm{C}$, while the warming magnitude is relatively small in the eastern parts of SWC and SC, less than $2{ }^{\circ} \mathrm{C}$. For the RCP4.5 scenario, the Tmin in the northern part of China would increase by $4-5^{\circ} \mathrm{C}$ in general, but more than $7{ }^{\circ} \mathrm{C}$ in the warming center, and in the southern part of China, the warming magnitude is approximately $3-4{ }^{\circ} \mathrm{C}$, with a smaller increase appearing in the southern part of SC, less than $3{ }^{\circ} \mathrm{C}$. For the RCP8.5 scenario, the increase magnitude is more than $6{ }^{\circ} \mathrm{C}$ in the northern part of China and TP, reaching $7^{\circ} \mathrm{C}$ in NWC and even exceeding $8^{\circ} \mathrm{C}$ in some areas of Xinjiang; however, the increases are relatively low in SC and the eastern part of Yunnan Province, only approximately $4-5{ }^{\circ} \mathrm{C}$ higher than the baseline level.

Figure 5 shows that, relative to the 1961-1990 reference period, there is a general increase in the annual Tmax and Tmin over China's land in the 21st century. The increase in TN5 is greater than that in the TX95 for all three RCP scenarios. The maximum temperature would increase by $2.4-6.2^{\circ} \mathrm{C}$ while the minimum would increase by $2.4-6.7^{\circ} \mathrm{C}$ compared to the baseline period. However, the Chinese territory presents a huge and diverse panel of climate types, and different regions may respond differently under future climate change. Interestingly, the eight sub-regions can be divided into two categories according to their regional differences in the warming rates between the Tmax and Tmin. The first type, including NWC, NEC, NC and TP, are mainly located in the high-latitude and high-elevation area of China, which is characterized by larger warming in the Tmin than in the Tmax under all of the RCP scenarios in the projected period. The asymmetry of the warming magnitudes between Tmax and Tmin is larger under higher-emission scenarios, in the order of RCP8.5, RCP4.5 and RCP2.6. NWC and NEC are typical regions, as shown in Figure 5. By the end of the 21st century, the differences in the warming magnitude (Tmin-Tmax) in NWC are $0.4{ }^{\circ} \mathrm{C}, 0.8^{\circ} \mathrm{C}$ and $1.1{ }^{\circ} \mathrm{C}$, respectively, under the RCP2.6, RCP4.5 and RCP8.5 scenarios. The higher warming rate in Tmin in these regions might be due to the reduction in the snow and ice cover under climate warming and that the increased water vapor content in a warmer atmosphere can obstruct the occurrence of extreme low temperatures in the high-latitude and high-elevation areas [4].

The second type of regions, including CC, SC, EC and SWC, are located in the southern and southeastern parts of China, which are characterized by larger warming in the Tmax than the Tmin under the three RCP scenarios. Two typical regions, CC and SC, are displayed to show the different trajectories in the changes of the Tmax and Tmin. Taking CC as a case study, by the end of the 21st century, the differences in the warming magnitude (Tmax-Tmin) are $0.8{ }^{\circ} \mathrm{C}, 0.3{ }^{\circ} \mathrm{C}$ and $0.4{ }^{\circ} \mathrm{C}$, respectively, under the RCP2.6, RCP4.5 and RCP8.5 scenarios. The higher warming rate in Tmax in these regions might be attributed to the decrease in soil moisture due to the excessive evaporation caused by the temperature increase, which results in a higher probability of extreme high temperatures $[4,7]$.

The high-temperature days characterized by the present-day threshold show a significant increase over 2071-2099 compared to 1961-1990, as shown in Figure 6. From a nationwide perspective, the HTD would increase by the largest magnitude under the RCP 8.5 scenario, followed by RCP4.5, and the least under the RCP2.6 scenario. The changes in HTD show a spatial feature that increases from the northern to the southern part of China. The smallest increase in HTD would appear in NEC, which may be due to its relatively low warming in the Tmax in this region, while the greatest increase in HTD would appear in the southern TP and SC under all three RCP scenarios. Under the RCP2.6 scenario, the increase in HTD is less than 5 days in most parts of NEC, and the increase is also relatively small in NWC and Yunnan Province, less than 20 days. However, it would increase by more than 30 days in 
the southern TP and CC as well as the southern part of SC, with the highest increase reaching 45 days. Under the RCP4.5 scenario, the increase in HTD in NEC and NWC is $15 \mathrm{~d} \sim 35 \mathrm{~d}$, which is much smaller compared to that in the southern TP, northeastern part of NWC and CC and EC as well as SC, where the increase in HTD is more than 50 days. In the RCP8.5 scenario, there is a general increase in HTD of more than 30 days nationwide. There is an increase of less than 40 days in northern NEC, which is the lowest increase in China; most of NWC would experience an increase of $60-65$ days. However, in the southern TP, western and southern parts of Sichuan, southern SC and the eastern coastal areas, there would be an increase in HTD by more than $100 \mathrm{~d}$, which indicates that the high-temperature extremes at the present-day level would become normal in the future. The high-temperature events in the southern part of China are fairly severe at present, but with further increases in the maximum temperature under climate change, there would be a substantial increase in the high-temperature extremes in the future, which may result in high pressure to the agricultural production and economic development as well as the energy supply in these regions [20]. Additionally, the TP is very sensitive to increases in the maximum temperature, due to the fragile ecosystem feature in this area, which may lead to severe impacts to the Tibetan Plateau from global warming.
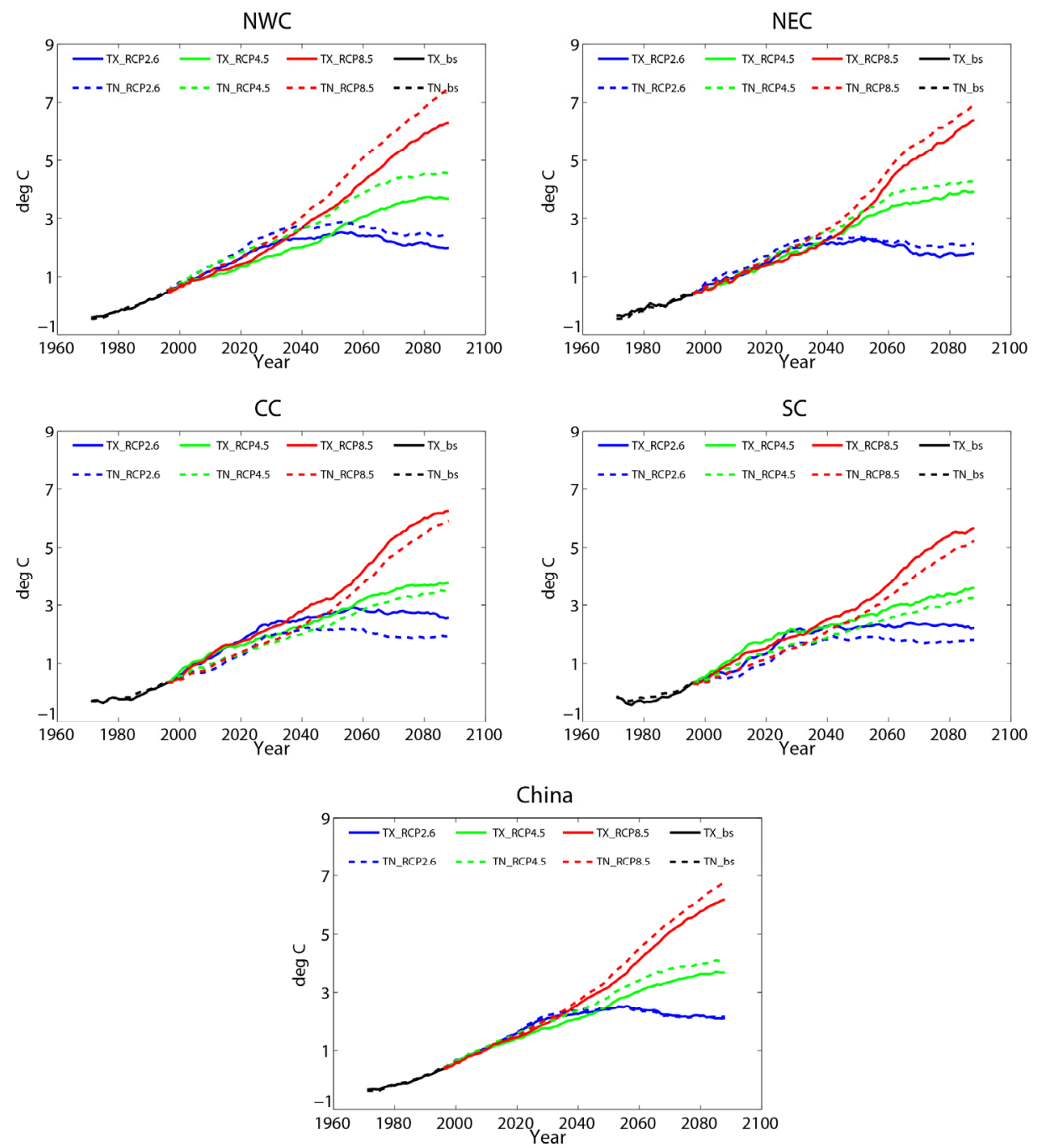

Figure 5. Asymmetrical warming between Tmax and Tmin in typical regions. All of the lines shown in the figure are the 20-year running averages of the time series. The red lines represent temperature changes under the RCP8.5 scenario, green for RCP4.5 and blue for RCP2.6; the solid lines represent Tmax and the dotted lines Tmin. 


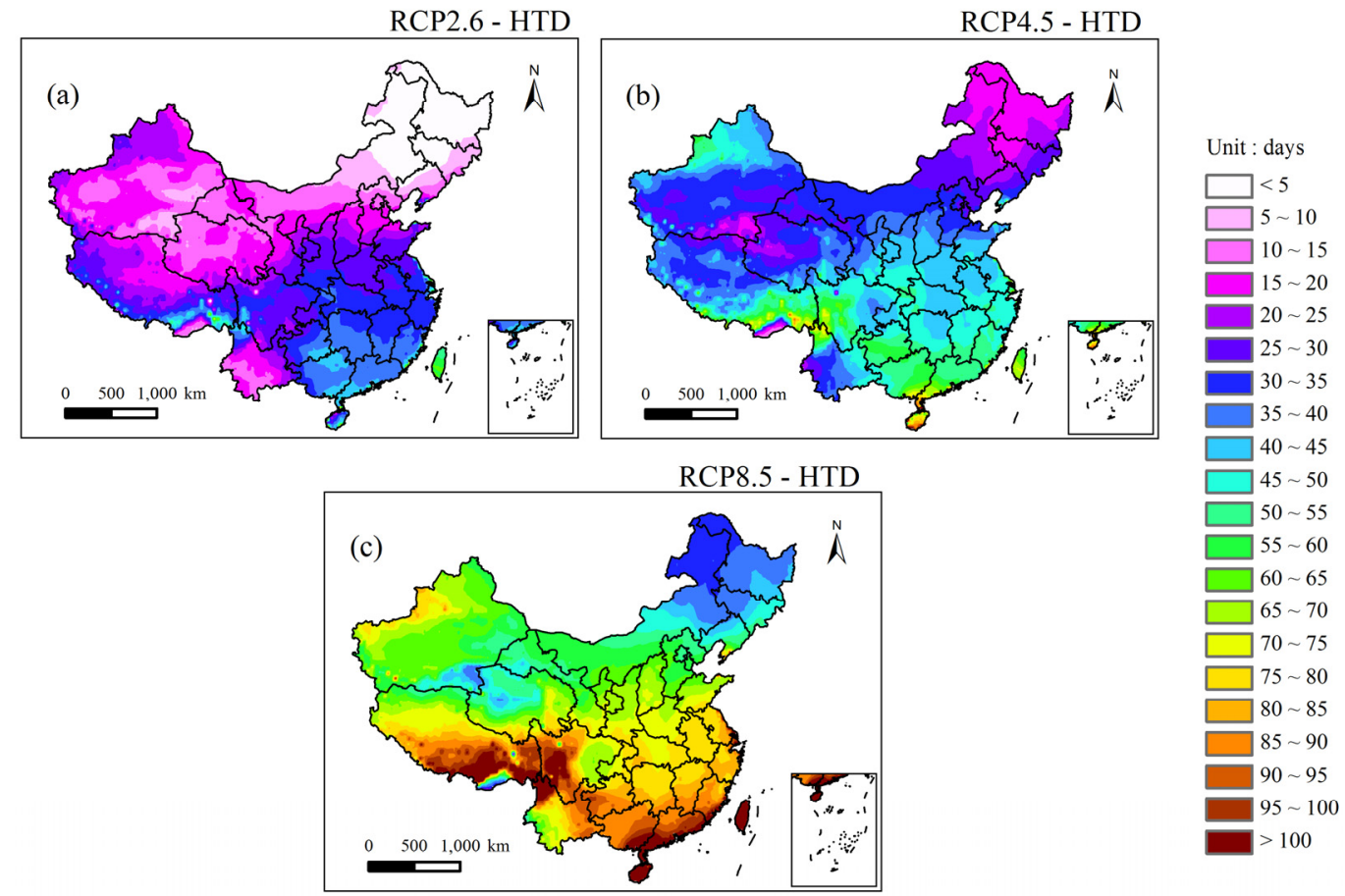

Figure 6. Changes of the HTD by the end of the 21st century compared to the baseline level under RCP2.6, RCP4.5 and RCP8.5 scenarios: (a) changes in HTD under RCP2.6 scenario; (b) changes in HTD under RCP4.5 scenario; and (c) changes in HTD under RCP8.5 scenario. Unit: days.

By the end of the 21st century, the low-temperature days based on the present-day level would decrease significantly under all three RCP scenarios (Figure 7). In common, a larger decrease in LTD appears in NEC, Xinjiang and the southeastern part of TP. Generally, there is the smallest decrease in LTD under the RCP2.6 scenario, while the largest decrease occurs under the RCP8.5 scenario, and there are some regional differences in the changes of LTD under the RCP scenarios. Under the RCP2.6 scenario, the largest decrease in LTD is located in the northern NEC and southern and eastern parts of Xinjiang, as well as the eastern TP, with a decrease of more than 13 days, while in southern NC, western EC, eastern part of Yunnan Province, southern SC and the southwestern TP, the decrease is less than 10 days. Under RCP4.5, the regions with larger decreases in LTD are relatively consistent with those under the RCP2.6 scenario, e.g., NEC, eastern TP and eastern and southern parts of Xinjiang, with decreases of more than 15 days, and some places in NEC would decrease by more than 18 days, while smaller decreases in LTD would appear in EC and SC, less than 15 days. For the RCP8.5 scenario, due to its severe warming in the minimum temperature, there would be a nationwide decrease in LTD of more than 15 days, in which NEC, northern NWC and the northern TP might experience reductions in LTD of more than 18 days, which suggests that under this emission scenario, there would hardly be a low-temperature day in most of China based on the present-day threshold.

Figure 8 shows that there is an opposite tendency between the projected HTD and LTD nationally under each of the RCP scenarios based on the present-day thresholds. Under the RCP2.6 scenario, the HTD shows a slight increasing tendency in the baseline period, and in the projected periods, it would increase quickly at first and then decrease slightly, while under the RCP4.5 scenario, it would increase a little slower than in RCP2.6 at first and keep on increasing until reaching stabilization by the end of the 21st century, and it would maintain a rapid increasing tendency under the RCP8.5 scenario. By the end of the 21 st century, the national mean HTD would increase by $106 \%, 196 \%$ and $346 \%$ over the baseline level under the RCP2.6, RCP4.5 and RCP8.5 scenarios, respectively. The national annual mean LTD has shown a decreasing trend in the baseline period, and in the projected periods, there are consistent tendencies of decreasing before the mid-21st century, and the LTD continues to decrease until there are 
few cold days based on the present-day threshold under the RCP8.5 scenario. However, it keeps on decreasing until stabilizing at approximately 2 days per year under the RCP4.5 scenario, and it would begin to recover in the latter part of the 21st century under the RCP2.6 scenario, which means that there might be a possibility of extreme cold events in the future. By the end of the 21st century, the LTD would decrease by $75 \%, 90 \%$ and $98 \%$ under the RCP2.6, RCP 4.5 and RCP 8.5 scenario, respectively. The analysis above may suggest that the frequency of the warm extremes would become much greater, while the cold extremes would become much more infrequent than the present-day level.

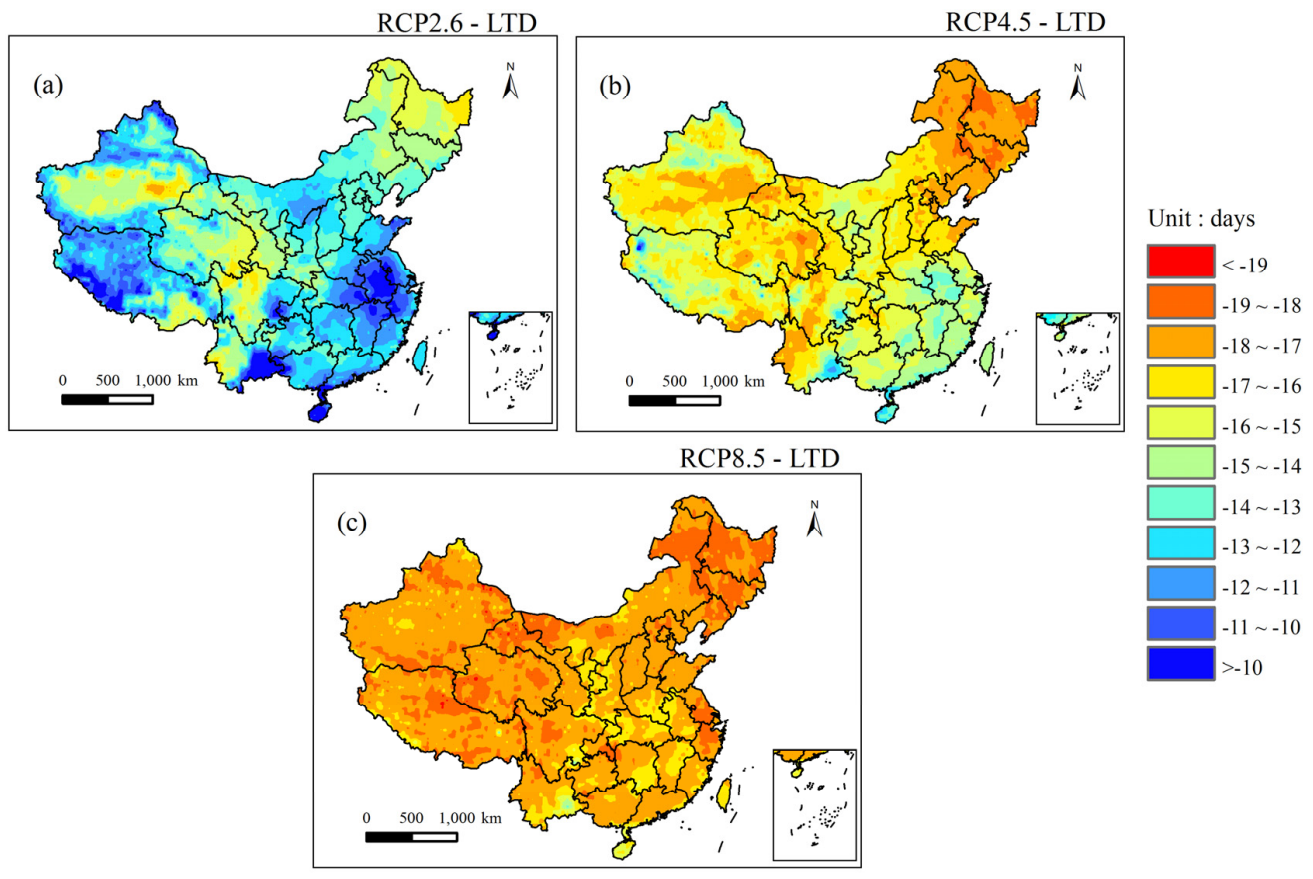

Figure 7. Changes of the LTD by the end of the 21st century compared to the baseline level under RCP2.6, RCP4.5 and RCP8.5 scenarios: (a) changes in LTD under RCP2.6 scenario; (b) changes in LTD under RCP4.5 scenario; and (c) changes in LTD under RCP8.5 scenario. Unit: days.
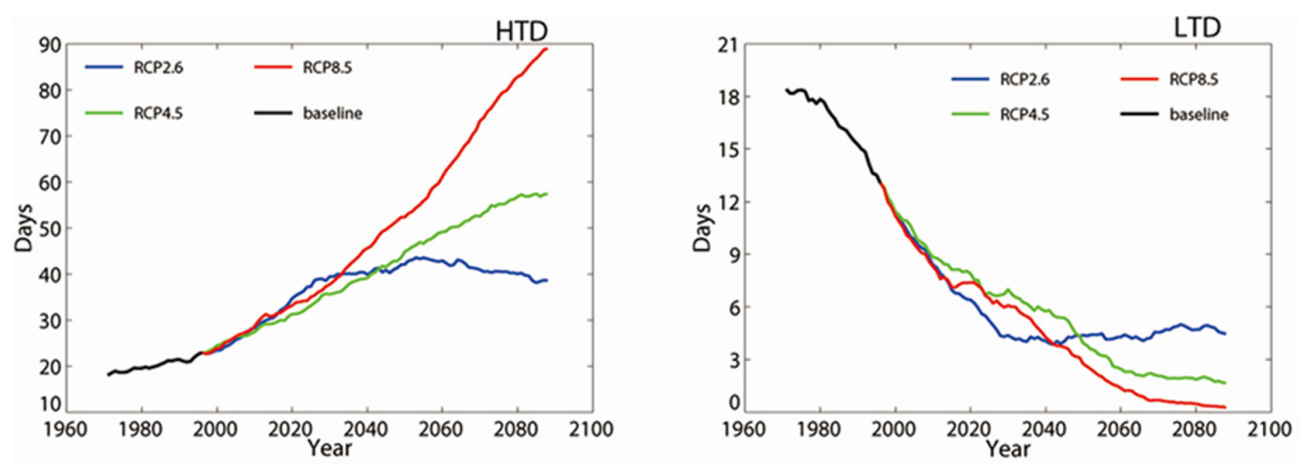

Figure 8. Twenty-year running average of the national mean extreme hot and cold days under the RCP scenarios in China.

The above results show that the thresholds for hot and cold extremes characterized by present-day levels might be inapplicable in the far future; therefore, there may be a need to recalculate the thresholds for temperature extremes by the end of the 21st century. It is shown in Figure 9 that by the end of the 21st century, both the TX95 and TN5 would be much warmer than those in the 1961-1990 reference period under all of the RCP scenarios. According to the statistics, TX95 would increase by $2.1^{\circ} \mathrm{C}$, $3.8^{\circ} \mathrm{C}$ and $6.3^{\circ} \mathrm{C}$ and the TN5 would increase by $3.4^{\circ} \mathrm{C}, 5.3^{\circ} \mathrm{C}$ and $8.1^{\circ} \mathrm{C}$ under the RCP2.6, RCP4.5 
and RCP8.5 scenarios, respectively, compared with the baseline level (Table not shown). This suggests that the intensity of the warm extremes would become more intensified, while the intensity of the cold extremes may be alleviated in the future. Obviously, there are some differences in the warming magnitudes of the TN5 and TX95; changes in TN5 are larger than those of TX95 in the national mean value. There are also some spatial differences in the changes of the thresholds for the warm extremes and cold extremes. Regions with higher increases in TX95 are mainly located in eastern SWC, CC and the northwest part of Xinjiang, while higher increases in TN5 are mainly distributed in the northern part of China, including NEC, NWC, northern NC, as well as the eastern TP. By the end of the 21st century (see Figure 9a,c,e), under the RCP2.6 scenario, the smallest increase in TX95 would appear in NEC, which is less than $1{ }^{\circ} \mathrm{C}$, while the largest increase in TX95 would occur in the Sichuan Basin, $\mathrm{CC}$ and SC, approximately $3-4{ }^{\circ} \mathrm{C}$. Under the RCP4.5 scenario, there is a minor increase of $1.5-2.5^{\circ} \mathrm{C}$ in the TX95 over the TP and the western part of Yunnan, while there are larger increases in TX95 in eastern SWC, in the range of $4-5^{\circ} \mathrm{C}$. For the RCP8.5 scenario, the changes are similar those under the RCP4.5 scenario, where TX95 would increase by more than $6{ }^{\circ} \mathrm{C}$ in most parts of China, and the highest increase in TX95 would be $7-9^{\circ} \mathrm{C}$ in the higher warming areas.

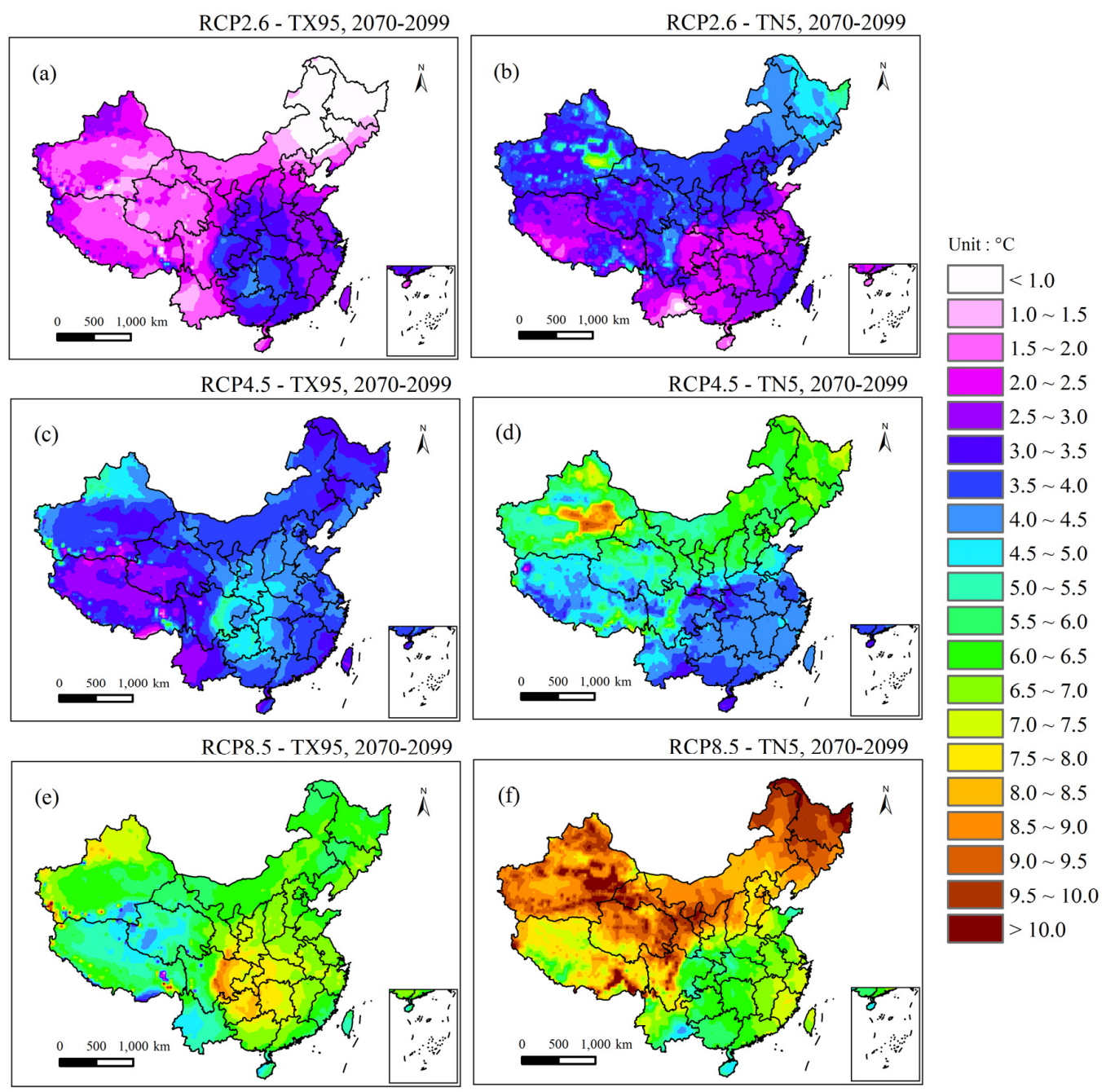

Figure 9. Changes of the TX95 and TN5 by the end of the 21st century compared to baseline level under RCP2.6, RCP4.5 and RCP8.5 scenario: (a) changes in TX95 under RCP2.6 scenario; (b) changes in TN5 under RCP2.6 scenario; (c) changes in TX95 under RCP4.5 scenario; (d) changes in TN5 under RCP4.5 scenario; (e) changes in TX95 under RCP8.5 scenario; and (f) changes in TN5 under RCP8.5 scenario. Unit: ${ }^{\circ} \mathrm{C}$. 
Unlike the spatial changes of TX95, the warming magnitude in TN5 would increase from south to north, showing the influence of latitude (see Figure $9 \mathrm{~b}, \mathrm{~d}, \mathrm{f}$ ). In addition, there is a warming center that is located in the eastern part of Xinjiang. By the end of the 21st century, under the RCP2.6 scenario, TN5 in the northern part of China would increase by $3-4{ }^{\circ} \mathrm{C}$, with more warming in northern NEC and the eastern part of Xinjiang, approximately $4.5-6^{\circ} \mathrm{C}$. A smaller increase in TN5 appears in the southern part of China and $\mathrm{TP}$, approximately $1-2.5^{\circ} \mathrm{C}$. Under the RCP4.5 scenario, the warming magnitude of the northern part of China is approximately $5-7^{\circ} \mathrm{C}$, and it even exceeds $8.5^{\circ} \mathrm{C}$ in the warming center. The lower warming areas in TN5 in the southern part of China would increase by $3-4.5^{\circ} \mathrm{C}$. Under the RCP8.5 scenario, there would be severe warming in the northern part of China and northeastern $\mathrm{TP}$, with a warming magnitude of approximately $8-10{ }^{\circ} \mathrm{C}$, and it would even exceed $10^{\circ} \mathrm{C}$ in some scattered areas. Some areas such as SC and the southwestern TP, though the warming magnitude is relatively small compared with that in the northern part of China, also warm more than $6{ }^{\circ} \mathrm{C}$ in general compared with the baseline level.

\section{Conclusions and Discussion}

In this paper, the daily maximum and minimum temperatures produced by PRECIS within China's boundary are used to test the simulation capability of the spatial distribution of the maximum and minimum temperatures as well as the extreme temperature indices, and then the changes of the extreme temperature events and the spatial and temporal variations compared to the baseline level are analyzed on regional and national scales. This is the first attempt to systematically analyze the changes in extreme temperature events under the low (RCP2.6), medium (RCP4.5) and high (RCP8.5) emission scenarios using the regional climate data produced by PRECIS.

In this study, the considerable simulation capability of PRECIS is testified first. From the comparisons of the spatial distributions of the observation and simulation: (1) PRECIS is less skilled at simulating the lower values in both the maximum and minimum temperature, which are mainly located in the Tibetan Plateau, implying that PRECIS may have deficiencies in simulating the snow-albedo feedbacks over cold regions. In addition, this is commonplace among almost all of the GCMs that there is an underestimation of the temperatures in the Tibetan Plateau $[15,23]$, which may because of the model deficiencies in simulating the cloud properties over the plateau, leading to insufficient plateau heating [15]. (2) There is a general overestimation of the temperatures in the subtropical south of China, which may be due to the inaccuracy in reproducing the cloud amount and aerosols in these regions by PRECIS. This is also detected in the simulations under the SRES scenarios in our previous study [37], and the departure is smaller under the RCP scenarios. This is accordance with the fact that GCMs tend to overestimate the high temperatures and underestimate the low temperatures in East Asia, according to the CMIP5 multi-model ensemble medians [7]. (3) The spatial discrepancy is larger in the western part than the eastern part of China, which may be due to the deficiency of the observation data and the complexity of the geographic features. The observatories in the western part of China are so sparse, and most of them located in areas with relatively low altitude over mountain regions, which resulted in deviations between the observation and the actual conditions [38]. Additionally, there is some discrepancy in the elevation data between the model and the real conditions, and it is known that climate models are sensitive to the altitude in temperature simulations [10]. How to eliminate these departures should be one of our concerns in future work.

As is projected by PRECIS, by the end of the 21st century, the maximum and minimum temperatures would be warmer than in the baseline period, and the changes are in agreement with the variability of the radiative forcing trajectories under the RCP scenarios. This is consistent with You and coworkers' projections of the changes of the maximum, mean and minimum temperatures of China [39], but the climate model - Max Planck Institute for Meteorology Earth Systems Model of low resolution (MPI-ESM-LR) that You et al. used in their study failed to capture the asymmetric trends for maximum and minimum projections. However, in our study, PRECIS projected it successfully. Nationally, Tmin would warm more than the Tmax under all of the RCP scenarios, but it is interesting 
that the asymmetrical warming features are projected to vary between different regions. There are mainly two types of asymmetrical warming, which are characterized by the difference between the warming magnitudes of Tmax and Tmin. Type 1, including NWC, NEC, NC and TP, is mainly in regions where snow and ice retreat with global warming, which would see a larger increase in Tmin than Tmax. NWC is a typical case of this group, where the asymmetrical warming is most significant in the future, which can be seen as a continuation of the current tendency [40]. In these regions, there is a positive response of the reduction in snow and ice cover and the increased water vapor content in a warmer atmosphere, which can obstruct the occurrence of extreme low temperatures [4]. Type 2, including CC, SC, EC and SWC, are mainly located in the warmer part of China and would experience a higher increase in maximum temperature than minimum temperature. As the maximum temperature has already reached a fairly high level at present [20], a further increase in Tmax may lead to more severe disasters related to the hot extremes in these regions.

By the end of the 21st century, there is a nationwide increase in HTD and a decrease in LTD characterized by the high and low thresholds for temperature at the present-day level. In the northern part of China, such as NEC and NWC, are more strongly respond to the changes in LTD, while the areas in southern part of China is more sensitive to changes in HTD. However, TP strongly responds to both of the changes in HTD and LTD, suggesting its high sensitivity to climate warming. In average, the HTD would increase by $106 \%, 196 \%$ and $346 \%$ compared to the baseline level, and a significant decrease in the LTD would appear, with a reduction of $75 \%, 90 \%$ and $98 \%$ by the end of the 21 st century. That is, the temperature extremes related to high temperatures at the present level would be more usual, while the extreme states related to the low temperatures would be less frequent in the future. Thus, it raises the demand to redefine the thresholds for the extreme temperatures in the future. Remarkable warming can be seen in the thresholds of the temperature extremes when comparing the changes in the TX95 (TN5) over 2070-2099 to that in the baseline period. The increases in temperature extremes can be controlled at a certain level under RCP2.6 scenario (policy-intervention scenario) [1], while the extreme temperature events would change greatly under RCP8.5 (the business-as-usual scenario) [1], which is projected to exceed the threshold for human adaptability [41]. The frequency and intensity of cold extremes would decrease in the future, while they are projected to increase significantly in the warm extremes. Therefore, it is necessary to reduce GHG emissions and take adaptation measures to control the increase in the warm events [22,42].

In our paper, we have made a series of analyses on the changes of extreme temperature events under the climate-policy-intervention scenarios, which can contribute to the impact and vulnerability assessment to climate change and provide scientific basis for the reduction in GHG emissions and take adaptation measures for China. In addition, our work also provides a complement to the impact and response database under climate change in developing countries.

Acknowledgments: We are very grateful to the anonymous reviewers for their constructive comments and thoughtful suggestions. The research leading to these results is financially supported from the Key Projects of China's national twelfth 5-year Science \& Technology Pillar Program (2013BAC09B04) and the Key 948 Project (2011-G9). We thank Dr. Changgui Wang for the technical support on PRECIS2.0 running.

Author Contributions: Yujing Zhang and Yinlong Xu conceived the topic of the work, Yujing Zhang and Liang Fu draw the figures and analyzed the results, Jie Pan provide the data quality control effort, Yujing Zhang wrote the paper. All authors read and approved the submitted manuscript and accepted the version for publication.

Conflicts of Interest: The authors declare no conflict of interest.

\section{References}

1. Stocker, T.F.; Qin, D.; Plattner, G.K.; Tignor, M.; Allen, S.K.; Boschung, J.; Nauels, A.; Xia, Y.; Bex, V.; Midgley, B.M. Climate Change 2013: The Physical Science Basis; Contribution of Working Group I to the Fifth Assessment Report of the Intergovernmental Panel on Climate Change; Cambridge University Press: Cambridge, UK; New York, NY, USA, 2013. 
2. Donat, M.G.; Alexander, L.V. The shifting probability distribution of global daytime and night-time temperatures. Geophys. Res. Lett. 2012, 39, L14707. [CrossRef]

3. Vose, R.S.; Easterling, D.R.; Gleason, B. Maximum and minimum temperature trends for the globe: An update through 2004. Geophys. Res. Lett. 2005, 32, L23822. [CrossRef]

4. Russo, S.; Sterl, A. Global changes in indices describing moderate temperature extremes from the daily output of a climate model. J. Geophys. Res. 2011, 116, D03104. [CrossRef]

5. Marengo, J.A.; Jones, R.; Alves, L.M.; Valverde, M.C. Future change of temperature and precipitation extremes in South America as derived from the PRECIS regional climate modeling system. Int. J. Climatol. 2009, 29, 2241-2255. [CrossRef]

6. Feng, S.; Hu, Q.; Huang, W.; Ho, C.H.; Li, R.; Tang, Z. Projected climate regime shift under future global warming from multi-model, multi-scenario CMIP5 simulations. Glob. Planet. Chang. 2014, 112, 41-52. [CrossRef]

7. Kharin, V.V.; Zwiers, F.W.; Zhang, X.; Wehner, M. Changes in temperature and precipitation extremes in the CMIP5 ensemble. Clim. Chang. 2013, 119, 345-357. [CrossRef]

8. Orlowsky, B.; Seneviratne, S.I. Global changes in extreme events: Regional and seasonal dimension. Clim. Chang. 2012, 110, 669-696. [CrossRef]

9. Sillmann, J.; Kharin, V.V.; Zwiers, F.W.; Zhang, X.; Bronaugh, D. Climate extremes indices in the CMIP5 multimodel ensemble: Part 2. Future climate projections. J. Geophys. Res. Atmos. 2013, 118, 2473-2493. [CrossRef]

10. Bennett, K.E.; Walsh, J.E. Spatial and temporal changes in indices of extreme precipitation and temperature for Alaska. Int. J. Climatol. 2015, 35, 1434-1452. [CrossRef]

11. Min, S.K.; Zhang, X.B.; Zwiers, F.; Shiogama, H.; Tung, Y.S.; Wehner, M. Multimodel detection and attribution of extreme temperature changes. J. Clim. 2013, 26, 7430-7451. [CrossRef]

12. Braganza, K.; Karoly, D.J.; Arblaster, J.M. Diurnal temperature range as an index of global climate change during the twentieth century. Geophys. Res. Lett. 2004, 31, L13217. [CrossRef]

13. Wang, K.; Ye, H.; Tang, L.N.; Chen, F.; Xiong, Y.Z.; Li, X.Y. Research progresses on diurnal temperature range: Variation trend and influential factors. Adv. Clim. Chang. Res. 2010, 6, 417-423. (In Chinese)

14. Editing Commission of the Third National Report on Climate Change of China. The Third National Report on Climate Change; Science Press: Beijing, China, 2015. (In Chinese)

15. Chen, L.; Frauenfeld, O.W. Surface air temperature changes over the twentieth and twenty-first centuries in China simulated by 20 CMIP5 models. J. Clim. 2014, 27, 3920-3937. [CrossRef]

16. $\mathrm{Xu}, \mathrm{C} . \mathrm{H} . ; \mathrm{Xu}, \mathrm{Y}$. The projection of temperature and precipitation over China under RCP scenarios using a CMIP5 multi-model ensemble. Atmos. Ocean. Sci. Lett. 2012, 5, 527-533.

17. Liu, Y.; Feng, J.; Ma, Z. An analysis of historical and future temperature fluctuations over China based on CMIP5 simulations. Adv. Atmos. Sci. 2014, 31, 457-467. [CrossRef]

18. Wang, L.; Chen, W. A CMIP5 multimodel projection of future temperature, precipitation, and climatological drought in China. Int. J. Climatol. 2014, 34, 2059-2078. [CrossRef]

19. Wang, H.J.; Sun, J.Q.; Chen, H.P.; Zhu, Y.L.; Zhang, Y.; Jiang, D.B.; Lang, X.M.; Fan, K.; Yu, E.T.; Yang, S. Extreme climate in China: Facts, simulation and projection. Meteorol. Z. 2012, 21, 279-304.

20. Sun, Y.; Zhang, X.; Zwiers, F.W.; Song, L.; Wan, H.; Hu, T.; Yin, H.; Ren, G. Rapid increase in the risk of extreme summer heat in Eastern China. Nat. Clim. Chang. 2014, 4, 1082-1085. [CrossRef]

21. China Climate Bulletin. Available online: http://www.cma.gov.cn/2011xwzx/2011xqxyw/20160112_301724. html (accessed on 12 January 2016).

22. Xu, X.; Du, Y.; Tang, J.; Wang, Y. Variations of temperature and precipitation extremes in recent two decades over China. Atmos. Res. 2011, 101, 143-154. [CrossRef]

23. Ji, Z.; Kang, S. Evaluation of extreme climate events using a regional climate model for China. Int. J. Climatol. 2015, 35, 888-902. [CrossRef]

24. Liu, J.; Du, H.; Wu, Z.; He, H.S.; Wang, L.; Zong, S. Recent and future changes in the combination of annual temperature and precipitation throughout China. Int. J. Climatol. 2016. [CrossRef]

25. Ramos, A.M.; Trigo, R.M.; Santo, F.E. Evolution of extreme temperatures over portugal: Recent changes and future scenarios. Clim. Res. 2011, 48, 177-192. [CrossRef] 
26. Yang, J.; Liu, H.Z.; Ou, C.Q.; Lin, G.Z.; Zhou, Q.; Shen, G.C.; Chen, P.Y.; Guo, Y.M. Global climate change: Impact of diurnal temperature range on mortality in guangzhou, China. Environ. Pollut. 2013, 175, 131-136. [CrossRef] [PubMed]

27. Zhang, X.; Alexander, L.; Hegerl, G.C.; Jones, P.; Tank, A.K.; Peterson, T.C.; Trewin, B.; Zwiers, F.W. Indices for monitoring changes in extremes based on daily temperature and precipitation data. Wiley Interdiscip. Rev.-Clim. Chang. 2011, 2, 851-870. [CrossRef]

28. Rajczak, J.; Pall, P.; Schär, C. Projections of extreme precipitation events in regional climate simulations for Europe and the Alpine Region. J. Geophys. Res.-Atmos. 2013, 118, 3610-3626. [CrossRef]

29. Boo, K.-O.; Kwon, W.-T.; Baek, H.-J. Change of extreme events of temperature and precipitation over Korea using regional projection of future climate change. Geophys. Res. Lett. 2006, 33, L01701. [CrossRef]

30. Moss, R.H.; Edmonds, J.A.; Hibbard, K.A.; Manning, M.R.; Rose, S.K.; van Vuuren, D.P.; Carter, T.R.; Emori, S.; Kainuma, M.; Kram, T.; et al. The next generation of scenarios for climate change research and assessment. Nature 2010, 463, 747-756. [CrossRef] [PubMed]

31. Rao, K.K.; Patwardhan, S.K.; Kulkarni, A.; Kamala, K.; Sabade, S.S.; Kumar, K.K. Projected changes in mean and extreme precipitation indices over India using PRECIS. Glob. Planet. Chang. 2014, 113, 77-90. [CrossRef]

32. Liu, C.B.; Ji, X.X.; Xu, Y.L.; Wang, M.X.; Zhang, L.; Pan, J.; Hu, Y.N.; Tong, J.H. Analysis of changes in the maximum and minimum temperature and diurnal temperature range from PRECIS model under the SRES A1B scenario for China. Clim. Environ. Res. 2015, 20, 89-96. (In Chinese)

33. Simmons, A.J.; Burridge, D.M. An energy and angular-momentum conserving vertical finite-difference scheme and hybrid vertical coordinates. Mon. Weather Rev. 1981, 109, 758-766. [CrossRef]

34. Jones, C.D.; Hughes, J.K.; Bellouin, N.; Hardiman, S.C.; Jones, G.S.; Knight, J.; Liddicoat, S.; O'Connor, F.M.; Andres, R.J.; Bell, C.; et al. The HadGEM2-ES implementation of CMIP5 centennial simulations. Geosci. Model Dev. 2011, 4, 543-570. [CrossRef]

35. Xu, Y.; Gao, X.J.; Shen, Y.; Xu, C.H.; Shi, Y.; Giorgi, F. A daily temperature dataset over China and its application in validating a RCM simulation. Adv. Atmos. Sci. 2009, 26, 763-772. [CrossRef]

36. Estévez, J.; Gavilán, P.; Giráldez, J.V. Guidelines on validation procedures for meteorological data from automatic weather stations. J. Hydrol. 2011, 402, 144-154. [CrossRef]

37. Xu, Y.L.; Pan, J.; Feng, Q. Projection on Future Climate Change in China-Constructing High Resolution SRES Climate Scenarios Using PRECIS; Science Press: Beijing, China, 2016.

38. Wu, J.; Gao, X.J. A gridded daily observation dataset over China region and comparison with the other datasets. Diqiu Wuli Xuebao 2013, 56, 1102-1111. (In Chinese)

39. You, Q.; Min, J.; Fraedrich, K.; Zhang, W.; Kang, S.; Zhang, L.; Meng, X. Projected trends in mean, maximum, and minimum surface temperature in China from simulations. Glob. Planet. Chang. 2014, 112, 53-63. [CrossRef]

40. Wang, B.; Zhang, M.; Wei, J.; Wang, S.; Li, S.; Ma, Q.; Li, X.F.; Pan, S.K. Changes in extreme events of temperature and precipitation over Xinjiang, northwest China, during 1960-2009. Quat. Int. 2013, 298, 141-151. [CrossRef]

41. Pal, J.S.; Eltahir, E.A.B. Future temperature in southwest Asia projected to exceed a threshold for human adaptability. Nat. Clim. Chang. 2015, 6, 197-200. [CrossRef]

42. Tebaldi, C.; Wehner, M.F. Benefits of mitigation for future heat extremes under RCP4.5 compared to RCP8.5. Clim. Chang. 2016, 1-13. [CrossRef]

(C) 2017 by the authors; licensee MDPI, Basel, Switzerland. This article is an open access article distributed under the terms and conditions of the Creative Commons Attribution (CC-BY) license (http://creativecommons.org/licenses/by/4.0/). 